\title{
Evaluation of knowledge sharing via E-Learning 2.0 in Enterprise
}

\author{
Wu Bing, Chen Wei \\ School of Economics and Management, Tongji university, China
}

\begin{abstract}
Keywords: Web 2.0; Enterprise Knowledge Community; SNS; Knowledge Sharing; Evaluation Indicator
\end{abstract}

Abstract. With the development of web 2.0 technology, knowledge sharing via E-Learning 2.0 has become important in enterprise. Evaluation of knowledge sharing as a reference of knowledge management can effectively reflect the company's business objectives and strategies. This paper proposes the evaluation method for the assessment of knowledge sharing via E-learning 2.0 system. Then the fuzzy theory is used to measure indicators of knowledge sharing in four dimensions, including organizational environment, perceptual practical, self-actualization, and social relationships. We use the case study to apply the proposed model, and the results can be used for knowledge sharing policy making. In the end, conclusions of the paper and future research direction are made.

\section{Introduction}

With the globalization of economy and the rapid development of science and technology, knowledge has replaced the traditional capital, labor and other factors as important strategic resources. Enterprises gradually focus on the knowledge capital, consequently knowledge becomes the most competitive enterprise resources. Knowledge sharing in the organization has become the research points in knowledge management.

Web 2.0 technologies make great changes in knowledge sharing. The goal of enterprise knowledge management is to enhance the competitive advantage by knowledge sharing. The implementation of knowledge sharing strategy within the enterprise, on the one hand is to avoid a repeated knowledge innovation input, a waste of resources; on the other hand, it is to improve the knowledge sharing capability.

The purpose of knowledge sharing research is to measure the factors related to enterprise knowledge sharing and evaluation, then according to the evaluation results, the existing problems can be found as the basis of policy improving for knowledge sharing.

How to make the enterprise internal knowledge sharing mechanism and test the effectiveness of knowledge sharing mechanisms? Therefore, this study establishes an evaluation method to effectively reflect harmonious of the knowledge strategy and to provide feedback mechanism to improve enterprise strategy, so as to achieve the goal of enterprise knowledge management. Firstly, the indicators are proposed for the evaluation of the knowledge sharing levels and effects. Secondly, according to the indicators, effective evaluation can be made. Finally, the measures can be improved to promote the knowledge sharing intention in line with organizational goals.

The rest of this article is organized as follows. We survey the relating research on knowledge sharing in virtual contexts. Then the evaluation system is proposed before it is applied in the case. In the end, the future research direction is concluded.

\section{Literature review}

The Theory of Rational Behavior. According to the theory of rational behavior (TRA), the behavioral attitude, subjective norm and perceived behavior control, influence behavior intention, which will affect the actual behavior ${ }^{1}$. The basic assumption of TRA is that people are rational for action decision making because people will integrate all kinds of information to consider the meaning and consequences of actions.

In the enterprise, the willing of employees in the knowledge community to exchange information and share knowledge, is largely based on the benefits of knowledge sharing. As a result, TRA combined with theory of Maslow's hierarchy of needs (Maslow 's hierarchy of needs) can be used to analyze the possible factors that affect the knowledge sharing.

E-Learning 2.0 Success Evaluation Model. E-Learning 2.0 success evaluation model shows that the information quality, system quality and service quality on the interaction and influence the quality of the 
user's satisfaction, and then apply to customer loyalty, and will eventually affect the user knowledge sharing behavior ${ }^{[2]}$.

A system success model can be used to find the key determinants for the perceived usefulness of the E-Learning 2.0 community. An E-Learning 2.0 community is designed for users to share information, collaborate with others, and obtain feedback. Thus, the factors driving the success of an E-Learning 2.0 community are drawn from the areas of interactive learning, cooperative learning, computer-mediated communication and online discussion boards.

Social Network. Virtual community is a social structure made of Nodes that are tied by one or more specific types of interdependency. Virtual community originates from six degrees of separation. A virtual community focuses on the building and verifying of online social networks for communities of people. Virtual community can be defined as an individual web page which enables online, human-relationship building by collecting useful information and sharing it with specific or unspecific people.

The existence of informal social networks within organizations has long been recognized as important and the unique working relationships among scientific and technical personnel have been well documented by both academics and practitioners. The growing interest in knowledge management practices has led to increased attention being paid to social network analysis as a tool for mapping the nature and membership of informal networks.

\section{The evaluation system of enterprise knowledge sharing}

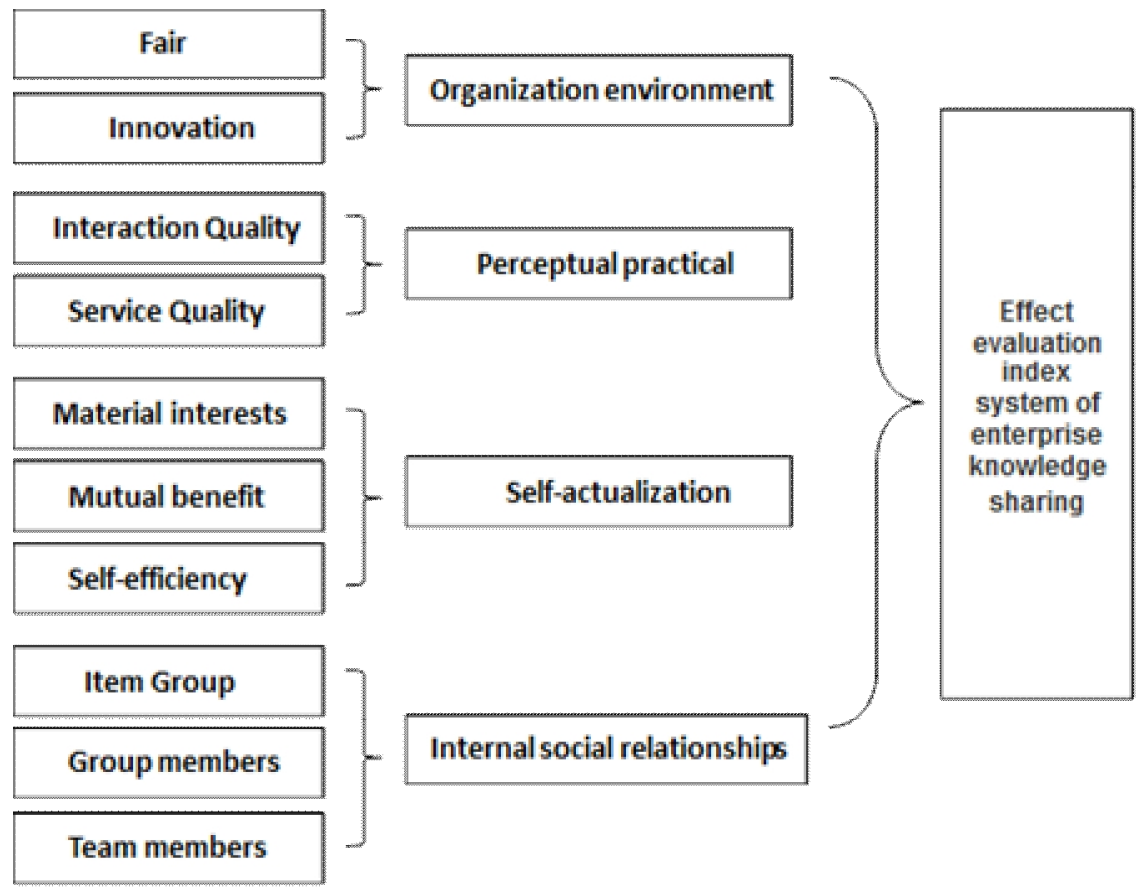

Figure 1 Evaluation system of enterprise knowledge sharing

The objective of E-Learning 2.0 communities is to enhance learning performance by encouraging participants to exploit or explore knowledge by reciprocal learning as a social process. Whether learners can share knowledge by raising good questions, recommending good articles, providing ideas and helping others resolve problems over E-Learning 2.0 communities becomes critical in enhancing their learning performance. Consequently, knowledge-sharing behavior is the most essential activity for maintaining and developing E-Learning 2.0 communities.

Although to evaluate the effect of knowledge sharing is significant, how to measure is a difficult problem. What are factors affect the knowledge sharing effects? What is the right perspective and method for evaluation? Currently, there is no unified opinion and idea about that. Based on previous studies, this paper establishes evaluation system of knowledge sharing from four dimensions, which are organization environment, perceptual practice, self-actualization and internal social relationships, as shown in Figure 1. 


\section{Case Study}

Background. X Airline Company in China is used for the case study, which is one of the state-owned air transport companies in China. The scope of business includes public air transportation, general aviation and air transport operations and the production and sale of related products, aviation equipment and equipment maintenance, passenger air transport, freight services and ground handling, aircraft leasing, and aviation training and consulting services.

$\mathrm{X}$ Airline Company owns 18 general aviation aircraft, provides air service to 151 countries, and has over 60,000 employees. In order to solving the problem of training for employees. Managers in X Airline Company introduced E-Learning system in 2005, then continually upgraded the system to E-Learning 2.0. Up to 2014, more than 90\% employees in the company have used the E-Learning 2.0 system to acquire knowledge for training.

In this paper, we use the evaluation system to evaluate the effect of knowledge sharing via E-Learning 2.0 of X Airline Company, then we provide the suggestion for knowledge sharing improvement.

Evaluation process. According to the evaluation model, we use the theory of fuzzy evaluation ${ }^{[4,5]}$ to analyze knowledge sharing via E-Learning 2.0 in X Airline Company. The weight of each indicator is shown in Table 1. Knowledge base is mainly used to measure the expert's experience and the process of establishing knowledge base.

\begin{tabular}{|c|c|c|c|c|c|c|}
\hline \multirow{2}{*}{ First-class index } & \multirow{2}{*}{ Second-class index } & \multicolumn{5}{|c|}{ the evaluation results and weights } \\
\hline & & A & $\mathrm{B}$ & $\mathrm{C}$ & $\mathrm{D}$ & $\mathrm{E}$ \\
\hline \multirow{2}{*}{$\begin{array}{c}\text { Organization } \\
\text { environment v1(0.15) }\end{array}$} & Fair F1(0.3) & 0.75 & 0.2 & 0.05 & 0 & 0 \\
\hline & Innovation $\mathrm{F} 2(0.7)$ & 0.5 & 0.25 & 0.15 & 0.1 & 0 \\
\hline \multirow{2}{*}{$\begin{array}{c}\text { Perceptual practical } \\
\text { v2(0.15) }\end{array}$} & $\begin{array}{c}\text { Interaction Quality } \\
\text { F3(0.4) }\end{array}$ & 0.25 & 0.1 & 0.5 & 0.05 & 0.1 \\
\hline & $\begin{array}{l}\text { Service Quality } \\
\text { F4(0.6) }\end{array}$ & 0.5 & 0.25 & 0.15 & 0.1 & 0 \\
\hline \multirow{3}{*}{$\begin{array}{l}\text { Self-actualization } \\
\qquad \text { v3(0.3) }\end{array}$} & $\begin{array}{l}\text { Material interests } \\
\text { F5(0.2) }\end{array}$ & 0.25 & 0.5 & 0.2 & 0.05 & 0 \\
\hline & mutual benefit $\mathrm{F} 6(0.3)$ & 0.8 & 0.15 & 0.05 & 0 & 0 \\
\hline & self-efficiency F7(0.5) & 0.4 & 0.1 & 0.5 & 0 & 0 \\
\hline \multirow{3}{*}{$\begin{array}{c}\text { Internal social } \\
\text { relationships v4(0.4) }\end{array}$} & Item Group F8(0.3) & 0.75 & 0.15 & 0.1 & 0 & 0 \\
\hline & $\begin{array}{l}\text { Group members } \\
\text { F9(0.3) }\end{array}$ & 0.7 & 0.2 & 0.1 & 0 & 0 \\
\hline & $\begin{array}{l}\text { Team members } \\
\text { F10 }(0.4)\end{array}$ & 0.8 & 0.1 & 0.1 & 0 & 0 \\
\hline
\end{tabular}

Weights of Second-class evaluation indicators were obtained through membership function. Through statistical analysis of the results from 10 experts, weight of each indicator can be gained.

On the basis of numerical blurred calculation, each expert will give an evaluation value about all second-class index, with the evaluation vector $S_{i}=\left(s_{i 1}, s_{i 2}, s_{i 3} \cdots, s_{i k}\right)$. For example, an expert evaluates 
"Innovation" indicator is 0.6 , according to Table 1 , we can easily know the evaluation vector is $(1,0,0,0,0)$; And if it is 0.4 , the evaluation vector is $(0,1,0,0,0)$.

For each second-class indicator of first-class evaluation vector, it usually be expressed as $A_{i}=F_{i} \times S$, there into $F_{i}$ is the $i$ First-class corresponding Second-class indexes, and $S$ stand for $j \times k$ evaluation matrix.

According to the weights vector of the first-class evaluation indicator $V=\left(v_{1}, v_{2}, v_{3} \cdots, v_{m}\right)$ and the first-class evaluation matrix $A$, it is easily to get the fuzzy evaluation matrix $B=V \times A=\left(b_{1}, b_{2}, b_{3} \cdots, b_{k}\right)$. Then the maximum membership degree principle is used to determine the final evaluation results, it's $b=\max \left(b_{1}, b_{2}, b_{3}, \cdots b_{k}\right)$.

In this case study, firstly, second-class indicators are evaluated by relevant experts and users of the E-Learning systems; secondly, the first-class evaluation matrix and the vector weights are calculated; finally, the comprehensive evaluation result is got at B level.

\section{Conclusion}

E-Learning 2.0 enables people to access relevant knowledge (explicit or tacit) from broader scope of resources. The performance in such environments is fundamentally based on how effectively the explicit and tacit knowledge can be shared across people, and how efficiently the created knowledge can be organized and disseminated to enrich digital content. Knowledge sharing requires collaboration between the consumers and contributors of knowledge; namely the collaborators.

This task cannot be accomplished simply by storing knowledge in the repository. It also requires a mechanism, which helps people find the collaborators with relevant knowledge. Collaboration via E-Learning 2.0 has characterized itself by heavily relying on interaction among the participations. Participations can be any virtual users who interact to achieve the goals of resources discovery, access, knowledge sharing, group communication and discussion.

Consequently, in future research, the evaluation system should be improved by concerning more reasonable indicators and objective methods according to the characteristics of E-Learning 2.0 system.

\section{References}

[1] DeLone,W.H., \& McLean, E.R..The DeLone and McLean model of information systems success: a ten-year update. Journal of Management Information Systems, 19(4):9-30 (2003)

[2] Hei Chia Wang, Yi Fang Chiu. Assessing e-learning 2.0 system success. Computers \& Education, 57: 1790-1800(2011).

[3] Konstantina ChrysafiadiVirvouMaria. PeRSIVA: An empirical evaluation method of a student model of an intellegent e-learning environment for computer programming, J. Computers \& Education. Vol. 68,p. 322-333 (2013)

[4] Ho C L, Dzeng R J. Construction safety training via E-Learning: Learning effectiveness and user satisfaction. Computers \& Education, 55(2), p. 858-867 (2010)

[5] Fang, Y.H., C.M. Chiu, 2010. In justice we trust: Exploring knowledge-sharing continuance intentions in virtual communities of practice. Computer Human Behavior, 26: 235-246

[6] Shiuann-Shuoh Chen, Yu-Wei Chuang, Pei-Yi Chen, 2012. Behavioral intention formation in knowledge sharing: Examining the roles of KMS quality, KMS self-efficacy, and organizational climate. Knowledge-Based Systems 31, 106-118 (2012)

[7] Suhwan Jeon, Young-Gul Kim, Joon Koh. An integrative model for knowledge sharing in communities-of-practice. JOURNAL OF KNOWLEDGE MANAGEMENT, 15(2), 251-269 (2011) 